\title{
Association of Functional Kallikrein-1 Promoter Polymorphisms and Acute Kidney Injury: A Case-Control and Longitudinal Cohort Study
}

\author{
Paweena Susantitaphonga, b Mary C. Perianayagam ${ }^{a}$ Sun Woo Kang ${ }^{c, d}$ \\ Wenyi Zhang ${ }^{c}$ Fangwen Rao ${ }^{c}$ Daniel T. O'Connor ${ }^{c}$ Bertrand L. Jaber ${ }^{a}$ \\ a Department of Medicine, Division of Nephrology, Kidney and Dialysis Research Laboratory, St. Elizabeth's \\ Medical Center, Boston, Mass., USA; ${ }^{b}$ Extracorporeal Multiorgan Support Dialysis Center, Division of Nephrology, \\ Department of Medicine, King Chulalongkorn Memorial Hospital, Faculty of Medicine, Chulalongkorn University, \\ Bangkok, Thailand; ' Department of Medicine, Center for Human Genetics and Genomics, University of California, \\ La Jolla, Calif., USA; ${ }^{d}$ Department of Nephrology, Inje University, Busan, Republic of South Korea
}

\section{Key Words}

Kallikrein-1 · Gene · Polymorphism · Promoter · Acute kidney injury

\begin{abstract}
Background: Kallikrein-1 (KLK1) is a highly conserved serine protease that is expressed in the kidney and involved in blood pressure regulation. The activity of this enzyme is diminished in acute kidney injury (AKI). Methods: We first evaluated the potential role of functional multiallelic KLK1 promoter gene polymorphisms in a case-control study of 481 subjects (214 hospitalized patients with AKI of mixed causes and 267 healthy subjects). The complex, multiallelic G/C-rich repeat region of the proximal $K L K 1$ promoter was determined by direct Sanger/capillary resequencing. Results: 16 alleles were identified in a complex, polymorphic $\mathrm{G} / \mathrm{C}$-rich region of the $K L K 1$ proximal promoter; 5 of these alleles $(\mathrm{F}, \mathrm{G}$, $\mathrm{H}, \mathrm{I}$, and $\mathrm{K}$ ) were associated with development of AKI. Alleles I and $\mathrm{G}$ were classified as risk-alleles (unadjusted OR 1.86; $95 \% \mathrm{Cl} 1.23,2.81 ; \mathrm{p}=0.003$ ), whereas alleles $\mathrm{F}, \mathrm{H}$, and $\mathrm{K}$ were classified as protective-alleles (unadjusted OR $0.32 ; 95 \% \mathrm{Cl}$ $0.22,0.46 ; p<0.001$ ) according to their directional association with development of AKI. After adjustment for sex, race,
\end{abstract}

preexisting chronic kidney disease and APACHE II score, the $K L K 1$ risk-allele (I or $\mathrm{G}$ ) carrier state was associated with the composite of $\geq 2$-fold increase in serum creatinine, oliguria, or dialysis requirement (adjusted OR $2.71 ; 95 \% \mathrm{Cl} 1.14,6.44$; $\mathrm{p}=0.02$ ). The $K L K 1$ risk-allele carrier state was also marginally associated with the composite of $\geq 2$-fold increase in serum creatinine, oliguria, dialysis requirement, or in-hospital death (adjusted OR 2.33; 95\% Cl 0.98, 5.52; $\mathrm{p}=0.06$ ). Conclusions: KLK1 promoter polymorphisms are associated with development of AKI and adverse outcomes. Further studies are needed to validate these findings.

Copyright $\odot 2013$ S. Karger AG, Basel

\section{Introduction}

Acute kidney injury (AKI) is an increasingly common and life-threatening complication in hospitalized patients $[1,2]$, conferring an increased short-term mortality risk, and a long-term risk of development of chronic kidney disease (CKD), kidney failure, and death [3, 4]. Unfortunately, AKI therapies that have been shown to be beneficial in experimental studies have often failed to demonstrate clinical efficacy $[5,6]$, due in part to untimely ini-

\section{KARGER}

E-Mail karger@karger.com www.karger.com/nec
(C) 2013 S. Karger AG, Basel

$1660-2110 / 13 / 1224-0107 \$ 38.00 / 0$
Bertrand L. Jaber, MD, MS

St. Elizabeth's Medical Center

736 Cambridge Street, Boston, MA 02135 (USA)

E-Mail bertrand.jaber@steward.org 
tiation of treatment. The identification of genetic risk markers that might influence the susceptibility to and severity of AKI, and improve individualized treatment is an emerging concept $[7,8]$. Several polymorphisms of genes encoding cytokines, oxidant stress enzymes, hypoxia-inducible factor- $\alpha$, and catecholamines have previously been shown to be associated with disease severity and adverse outcomes in patients with AKI [9-13].

Kallikreins are a subgroup of serine proteases with diverse physiological functions. Kallikrein-1 (KLK1), one of 15 kallikrein family members, is the major kallikrein expressed in the kidney, where it generates kinins, including lysyl-bradykinin and bradykinin [14]. KLK1 is involved in kidney function and blood pressure regulation through vasodilatory and natriuretic effects. Kidney tissue levels of KLK1 are decreased in experimental settings of hypertension [15], diabetic nephropathy [16], high salt- and aminoglycoside-induced kidney injury $[17,18]$.

KLK1 is encoded by the KLK1 gene, which is located on chromosome 19q13.3. In experimental models of AKI, KLK1 gene transfer can attenuate the severity of kidney injury [19-21]. In human AKI, a biphasic response of urinary KLK1 excretion has been observed, with an initial decrease followed by an increase, as a result of activation of the adrenergic pathway [22]. There is a complex, highly polymorphic ( 16-allele) G/C-rich region of approximately 120 base pairs upstream of the transcription initiation site in the human $K L K 1$ promoter, whose multiple alleles influence promoter activity of the gene [23]. Polymorphisms at this site have been identified in the general population [23] and subsequently associated with CKD $[24,25]$.

In the present study, using a case-control design and a candidate allele approach, we first examine the association of the multiallelic KLK1 promoter region polymorphisms with the development of hospital-acquired AKI in an adult population, identifying both risk- and protective-alleles for susceptibility to AKI. We next explore the association of the KLK1 polymorphic risk-alleles with kidney-related adverse outcomes in patients with AKI.

\section{Methods}

\section{Study Populations}

Cases consisted of hospitalized patients with AKI recruited from two acute care facilities (Boston, Mass., USA) between November 2003 and January 2007. All eligible patients were $\geq 18$ years of age and received in-hospital nephrology consultation for AKI of mixed causes. Exclusion criteria were pregnancy and long-term dialysis dependence. Control subjects consisted of non-hospital- ized healthy adults $\geq 18$ years of age with no known kidney disease who were also genotyped for the same KLK1 promoter allele polymorphisms. Informed consent was obtained for each subject and institutional review board approval was granted.

\section{Data Collection}

For the AKI cohort, data collection included baseline demographic characteristics, comorbid conditions, 24-hour urine output at enrollment, and serial serum creatinine values. Sepsis was ascertained using the systemic inflammatory response syndrome criteria [26], and two severity-of-illness scores were calculated, the Acute Physiology and Chronic Health Evaluation (APACHE) II score [27], and the Multiple Organ Failure (MOF) score [28]. The baseline serum creatinine was defined as a stable value prior to the acute rise representing the AKI event under study. Using this baseline serum creatinine value, preexisting CKD was defined on the basis of an estimated glomerular filtration rate $<60 \mathrm{ml} / \mathrm{min} / 1.73 \mathrm{~m}^{2}$, which was calculated using the Modification of Diet in Renal Disease study equation [29]. Oliguria at enrollment was defined as a 24-hour urine output $<400 \mathrm{ml}$. At enrollment, AKI was reclassified according to the AKI network staging system, using serum creatinine-based criteria [30]. For biogeographic ancestry, self-identified ethnicity was used.

\section{Genotyping Analyses}

For both cohorts, EDTA-anticoagulated whole blood was collected and aliquoted for subsequent DNA extraction. Genomic DNA was prepared using a QiAmp DNA blood kit or Gentra Puregene columns (both from Qiagen, Valencia, Calif., USA).

The complex, multiallelic, G/C-rich polymorphic region of the human KLK1 promoter [23] was evaluated by resequencing of the isolated genomic DNA. In brief, PCR amplification of the polymorphic region was performed as previously described [31] using forward primer hKPM6 and reverse primer hKPM7 [23]. PCR products were treated with exonuclease I and shrimp alkaline phosphatase to remove primers and dNTPs prior to cycle sequencing with BigDye terminators (Applied Biosystems, Foster City, Calif., USA). Sequence was determined from each direction (both sense and antisense strands) on an ABI-3100 automated sequencer, with visualization of sequence by system software as well as visual inspection of sequence tracings in each subject, to assign diploid genotypes.

\section{Statistical Analysis}

Genotype frequencies for each KLK1 promoter polymorphism in the control subjects and the AKI cohort were examined for deviation from Hardy-Weinberg equilibrium using the $\chi^{2}$ test. Additive genetic logistic regression models (i.e. per allele copy increase) were used to assess the association of the KLK1 promoter polymorphic risk- and protective-alleles with development of AKI, after adjustment for age, sex, race, and presence of hypertension, diabetes mellitus, and preexisting CKD.

For the AKI cohort, comparisons of baseline characteristics and outcomes between the KLK1 polymorphic risk- and non-riskallele groups were performed using Student's $t$ test or analysis of variance for normally distributed continuous variables, and nonparametric Wilcoxon rank sum or Kruskal-Wallis tests for nonnormally distributed variables. $\chi^{2}$ or Fisher exact tests were used for categorical variables. In consideration of testing the effects of multiple correlated alleles (or diploid genotypes) at a locus on a trait, we employed estimation of the false discovery rate (FDR) in 
Table 1. Observed KLK1 allele distribution in healthy control subjects and the AKI cohort

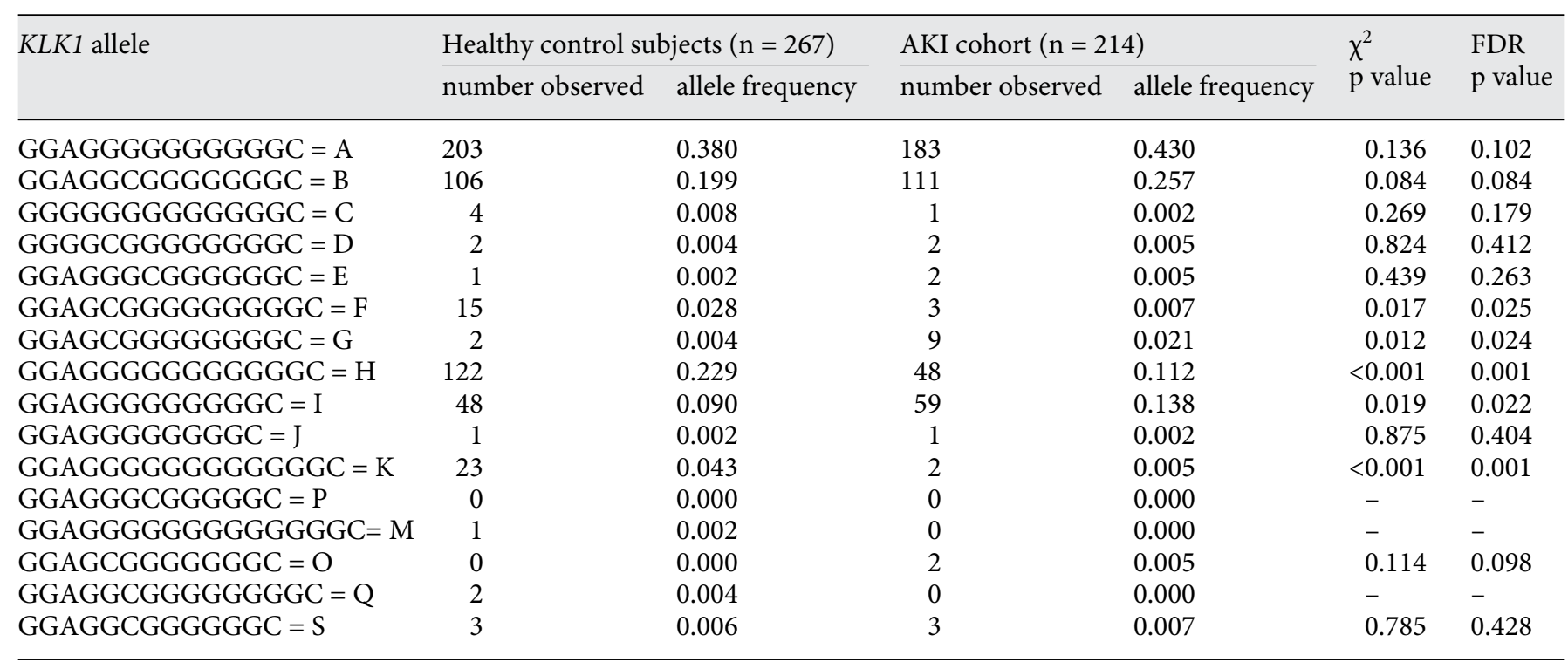

A global $\chi^{2}$ test on this $2 \times 16$ (healthy control subjects vs. AKI cohort; 16 alleles) contingency table yielded a $\chi^{2}$ value $=60.97$ and $\mathrm{p}$ value $<0.001$.

order to minimize false negative results while maximizing false positive results, using the Excel calculator of FDRs from $p$ values (http://www.rowett.ac.uk/ gwh/fdr.html).

Additive genetic (per 1-allele copy increase) logistic regression models were also used to assess the association of $K L K 1$ promoter polymorphic alleles with the composite kidney-related outcome of $\geq 2$-fold increase in serum creatinine representing stage 2 and 3 AKI according to the AKI network classification [30], oliguria, or dialysis requirement. The models were adjusted for sex, race, preexisting CKD and APACHE II score.

Sensitivity analyses restricted to white subjects were performed in both the case-control study and the AKI cohort. The data are presented as frequencies with proportions, and means with standard deviations. The results of the logistic regression analyses are displayed as odds ratios (OR) with $95 \%$ confidence interval (CI). All the statistical analyses were performed using the SPSS statistical package (version 11.5 for Windows; SPSS, Inc., Chicago, Ill., USA). Differences were considered statistically significant at a $\mathrm{p}$ value $<0.05$.

\section{Results}

\section{Characteristics of the Control Subjects and the AKI Cohort}

A total of 481 subjects were included for the case-control analysis, of whom 267 were healthy non-hospitalized control subjects and 214 hospitalized patients with a diagnosis of AKI (online suppl. table 1; for all online suppl. material, see www.karger.com/doi/10.1159/000350733).
The control subjects had a mean age of $41.5 \pm 16.5$ years, $26 \%$ were men, $82 \%$ were white, $13 \%$ had hypertension, $2 \%$ had diabetes, and $8 \%$ had preexisting CKD. The mean age of the AKI cohort was $64.5 \pm 15.9$ years, $54 \%$ were men, and $91 \%$ were white. The prevalence of hypertension, diabetes, and preexisting CKD was 75,44 , and $73 \%$, respectively, which was significantly different from control subjects ( $\mathrm{p}<0.001$ for all analyses). The biogeographic ancestry (ethnicity) distribution also differed between the two groups $(\mathrm{p}<0.001)$.

$92(43 \%)$ patients with AKI required dialysis and 51 (24\%) died. The majority of patients had severe AKI as defined by the AKI network criteria. In brief, 66 (31\%) patients suffered from stage 1, $12(6 \%)$ from stage 2 , and 136 (63\%) from stage 3 AKI.

\section{Association of KLK1 Promoter Polymorphisms with Development of $A K I$}

A total of $16 K L K 1$ alleles were identified and the observed allele distribution in the control subjects and AKI cohort is shown in table 1 with discernable differences (global $\mathrm{p}<0.001$ by $\chi^{2}$ test). We identified $5 K L K 1$ alleles, including alleles $F, G, H, I$, and $K$, to be significantly associated with development of AKI (table 2). The I and G alleles were classified as risk-alleles, whereas the $\mathrm{F}, \mathrm{H}$, and $\mathrm{K}$ alleles were classified as protective-alleles, according to their 
Table 2. Association of $K L K 1$ alleles with development of AKI $(\mathrm{n}=481)$

\begin{tabular}{llc}
\hline KLK1 allele & OR $(95 \%$ CI $)$ & p value \\
\hline $\begin{array}{l}\text { Allele I (per allele copy } \uparrow) \\
\quad \text { Unadjusted }\end{array}$ & $1.68(1.10,2.56)$ & 0.016 \\
$\begin{array}{l}\text { Allele G (per allele copy } \uparrow) \\
\quad \text { Unadjusted }\end{array}$ & $4.48(0.92,21.80)$ & 0.063 \\
$\begin{array}{l}\text { Risk (I or G)-allele (per allele copy } \uparrow) \\
\quad \text { Unadjusted }\end{array}$ & $1.86(1.23,2.81)$ & 0.003 \\
$\quad$ Adjusted & $1.86(0.95,3.66)$ & 0.072 \\
$\begin{array}{l}\text { Allele F (per allele copy } \uparrow) \\
\quad \text { Unadjusted }\end{array}$ & $0.26(0.07,0.91)$ & 0.035 \\
$\begin{array}{l}\text { Allele H (per allele copy } \uparrow) \\
\quad \text { Unadjusted }\end{array}$ & $0.34(0.23,0.51)$ & $<0.001$ \\
Allele K (per allele copy $\uparrow)$ & $0.10(0.02,0.43)$ & 0.002 \\
$\quad$ Unadjusted & $0.32(0.22,0.46)$ & $<0.001$ \\
Protective (F, H, or K)-allele (per allele copy $\uparrow)$ & $<0.001$ \\
$\quad$ Unadjusted & $0.34(0.19,0.62)$ & \\
$\quad$ Adjusted & & \\
\hline$\quad$ Analysis adjusted for age, sex, race, hypertension, diabetes, and pre- & \\
existing CKD. & &
\end{tabular}

Table 3. Characteristics and outcomes of the AKI cohort stratified according to $K L K 1$ polymorphic risk- vs. non-risk-alleles $(\mathrm{n}=214)$

\begin{tabular}{|c|c|c|c|}
\hline Variable & $\begin{array}{l}\text { Risk-allele } \\
\text { (allele I or G) } \\
(\mathrm{n}=63)\end{array}$ & $\begin{array}{l}\text { Non-risk-allele } \\
\text { (other alleles) } \\
(\mathrm{n}=151)\end{array}$ & $\begin{array}{l}\mathrm{p} \\
\text { value }\end{array}$ \\
\hline Age, years & $62.9 \pm 14.5$ & $65.2 \pm 16.5$ & 0.31 \\
\hline Men, $\mathrm{n}$ & $34(54)$ & $81(54)$ & 0.97 \\
\hline White ethnicity, n & $57(90)$ & $138(91)$ & 0.87 \\
\hline \multicolumn{4}{|l|}{ Cause of AKI, $\mathrm{n}$} \\
\hline Ischemic & $13(21)$ & $46(31)$ & 0.14 \\
\hline Nephrotoxic & $12(19)$ & $20(13)$ & 0.28 \\
\hline Sepsis & $9(14)$ & $11(7)$ & 0.11 \\
\hline Multifactorial/other & $29(46)$ & $74(49)$ & 0.69 \\
\hline \multicolumn{4}{|l|}{ Coexisting conditions, $\mathrm{n}$} \\
\hline Diabetes mellitus & $28(44)$ & $66(44)$ & 0.92 \\
\hline Hypertension & $46(73)$ & $114(75)$ & 0.70 \\
\hline Cardiovascular disease & $36(57)$ & $91(60)$ & 0.67 \\
\hline Liver cirrhosis & $7(11)$ & $11(7)$ & 0.39 \\
\hline Chronic lung disease & $14(22)$ & $21(14)$ & 0.13 \\
\hline Chronic kidney disease & $45(71)$ & $111(74)$ & 0.47 \\
\hline Sepsis, n & $30(48)$ & $67(44)$ & 0.66 \\
\hline APACHE II score & $19.7 \pm 6.8$ & $20.0 \pm 6.4$ & 0.84 \\
\hline MOF score & $1.2 \pm 1.0$ & $1.1 \pm 0.9$ & 0.56 \\
\hline \multicolumn{4}{|l|}{ AKI network stage, $\mathrm{n}$} \\
\hline Stage 1 & $16(25)$ & $50(33)$ & 0.27 \\
\hline Stage 2 & $6(10)$ & $6(4)$ & 0.10 \\
\hline Stage 3 & $41(65)$ & $95(63)$ & 0.76 \\
\hline Enrollment urine output, $\mathrm{ml} /$ day & $979 \pm 827$ & $1,274 \pm 1,063$ & 0.03 \\
\hline Oliguria at enrollment, $\mathrm{n}$ & $18(29)$ & $31(21)$ & 0.21 \\
\hline $\begin{array}{l}\geq 2 \text {-Fold increase in serum } \\
\text { creatinine, } n\end{array}$ & $47(75)$ & $98(65)$ & 0.26 \\
\hline Dialysis requirement, $\mathrm{n}$ & $30(48)$ & $62(41)$ & 0.38 \\
\hline In-hospital mortality, $\mathrm{n}$ & $17(27)$ & $34(23)$ & 0.48 \\
\hline
\end{tabular}

Values in parentheses are percentage. directional association with development of AKI. Among the significant $(\mathrm{p}<0.05)$ risk-alleles (I and $\mathrm{G})$, allele I had a relatively common frequency of $9.0-13.8 \%$, and among the protective-alleles ( $\mathrm{F}, \mathrm{H}$, and $\mathrm{K}$ ), allele $\mathrm{H}$ had a common frequency of $11.2-22.9 \%$. Tests for Hardy-Weinberg equilibrium showed no significant deviation from expected frequencies $(\mathrm{p}=0.15)$ for all alleles (online suppl. table 2$)$.

The results of the unadjusted and adjusted genetic additive models for individual and combined polymorphic alleles are displayed in table 2 . Each copy increase in the $K L K 1$ protective-allele $(\mathrm{F}, \mathrm{H}$, or $\mathrm{K})$ was significantly associated with a lower unadjusted and adjusted OR for development of AKI. By contrast, each copy increase in the $K L K 1$ risk-allele (I or G) was significantly associated with a higher unadjusted OR for development of AKI, which became non-significant in the adjusted analysis (table 2). In sensitivity multivariable analyses restricted to the subset of white subjects $(\mathrm{n}=413)$, increasing copies of both KLK1 protective- and risk-alleles remained significantly associated with development of AKI (online suppl. table 3).

\section{Association of KLK1 Risk-Alleles with Kidney-Related Endpoints in the AKI Cohort}

We next examined the association of the risk-allele (I or $\mathrm{G}$ ) with individual kidney-related endpoints, and the composite of $\geq 2$-fold increase in serum creatinine, oliguria, or dialysis requirement. As shown in table 3, the riskallele was associated with an adjusted OR for the composite kidney-related endpoint of $\geq 2$-fold increase in serum creatinine, oliguria or dialysis requirement, after adjustment for sex, race, preexisting CKD, and APACHE II score (adjusted OR 2.71; 95\% CI 1.14, 6.44; $\mathrm{p}=0.02$ ). Although there was no association between the risk-allele and the individual components of the composite endpoint (table 4), the risk-allele group was associated with an adjusted OR of 2.3 for the composite outcome, which reached near significance $(\mathrm{p}=0.06)$.

In sensitivity multivariable analyses restricted to the subset of white subjects $(\mathrm{n}=195)$, increasing copies of the $K L K 1$ risk-allele remained associated with the two composite outcomes (online suppl. table 4).

\section{Discussion}

In the present study, we examined the association of functional KLK1 promoter polymorphisms with the development of AKI in a hospitalized adult population. Five alleles, including alleles F, G, H, I, and K, were found to be associated with development of AKI, and confirmed 
Table 4. Association of the $K L K 1$ risk-allele (I or G) with adverse outcomes in the AKI cohort $(n=214)$

\begin{tabular}{lcc}
\hline Outcome variable & OR $(95 \% \mathrm{CI})$ & p value \\
\hline $\begin{array}{l}\text { 22-Fold increase in serum creatinine } \\
\quad \text { Unadjusted }\end{array}$ & $1.38(0.73,2.60)$ & 0.318 \\
$\quad$ Adjusted & $1.56(0.78,3.12)$ & 0.209 \\
Oliguria & $1.49(0.80,2.77)$ & 0.206 \\
$\quad$ Unadjusted & $1.50(0.77,2.90)$ & 0.233 \\
$\quad$ Adjusted & $1.44(0.83,2.50)$ & 0.195 \\
$\begin{array}{l}\text { Dialysis requirement } \\
\quad \text { Unadjusted }\end{array}$ & $1.54(0.85,2.81)$ & 0.155 \\
$\quad$ Adjusted & & \\
$\geq 2$-Fold increase in serum creatinine, & & \\
$\quad$ oliguria, or dialysis requirement & $2.09(0.94,4.68)$ & 0.072 \\
$\quad$ Unadjusted & $2.71(1.14,6.44)$ & 0.024 \\
$\quad$ Adjusted & $1.26(0.68,2.35)$ & 0.459 \\
In-hospital death & $1.38(0.64,2.98)$ & 0.406 \\
$\quad$ Unadjusted & & \\
$\quad$ Adjusted & & \\
$\geq 2$-Fold increase in serum creatinine, oliguria, & \\
$\quad$ dialysis requirement, or in-hospital death & $1.88(0.84,4.21)$ & 0.126 \\
$\quad$ Unadjusted & $2.33(0.98,5.52)$ & 0.056 \\
$\quad$ Adjusted &
\end{tabular}

Adjustment variables were sex, race, preexisting CKD and the APACHE II score.

by FDR analysis; I and G were classified as risk-alleles, while $\mathrm{F}, \mathrm{H}$, and $\mathrm{K}$ were classified as protective-alleles, according to their directional association with development of AKI. In patients with AKI, the risk-alleles were found to be associated with disease severity, including the composite of $\geq 2$-fold increase in serum creatinine, oliguria, or dialysis requirement.

There are only a limited number of studies of the KLK1 system in human AKI. An early report found that patients with AKI after kidney transplantation exhibited diminished urinary KLK1 excretion [32]. More recently, patients with AKI were found to have a biphasic response in urinary KLK1 enzymatic activity excretion, likely the result of activation of the adrenergic system in the setting of volume contraction [22]. In another study of 6 patients with ischemic acute tubular necrosis, urinary KLK1 excretion reached the highest level before resolution of oliguria [33]. In an animal model of AKI, renal KLK1 expression was persistently reduced in the kidney after functional recovery from ischemic injury [34]. In our study, carriers of the KLK1 risk-allele displayed significantly decreased urine output, suggesting indirectly that this allele might be associated with lower kidney KLK1 enzymatic activity.

In a recent study, the experimental implantation of KLK1-modified mesenchymal stem cells into the kidney provided apparent protection against ischemia-induced AKI, as evidenced by reduced blood urea nitrogen, serum creatinine, and tubular injury [35]. KLK1 gene transfer has also been shown to attenuate the decline in kidney function in a rodent model of CKD involving 5/6 nephrectomy [36]. The KLK1 system has been proposed to play a role in hypertension, but its role in human AKI has thus far been incompletely explored. Evaluation of additional candidate genes associated with KLK1 biosynthesis, catabolism, and function could be undertaken in this setting. Potential novel interventions into the KLK1 system might provide alternative treatment options for AKI management in the future.

To our knowledge, this is the first study to test the hypothesis of whether these functional KLK1 promoter polymorphisms associate with development of AKI and adverse clinical outcomes. Strengths of the analyses include the demonstrable associations between $K L K 1$ promoter polymorphisms and development of AKI and adverse outcomes. The AKI cohort was well characterized with prospectively collected data and ascertainment of clinically meaningful kidney-related endpoints, and no attrition or loss to follow-up. There are several limitations however that should be noted. For control subjects, we used a nonhospitalized adult population with no known kidney disease; although we adjusted for potentially important factors such as age, sex, ethnicity, hypertension, diabetes, and preexisting CKD, we could not control for factors associated with hospitalization per se, which might alter KLK1 activity. In addition, the biogeographic ancestry distribution differed between cases and control subjects. Although we had ancestry-informative markers on the control subjects, we did not perform ancestry-informative markers on the AKI cohort. To overcome this important limitation, we adjusted our analyses for race and performed sensitivity analyses restricted to white subjects. Based on the inclusion criteria used in the study, we included patients with more severe stages of AKI and a higher percentage of preexisting CKD, which likely resulted in a higher percentage $(43 \%)$ of patients requiring dialysis. These selection biases likely reduce the generalizability of our findings. Another important limitation is the relatively small sample size for a gene association study of a very complex trait, as well as a multiallelic promoter polymorphism with both common and infrequent alleles, likely enhancing the chance of false negatives (or type II error) for some of our attempted allelic associations. We also acknowledge that dialysis initiation and management of oliguria is subject to variability among physicians and was likely influenced by patient and physician factors. We enrolled subjects with AKI at the time of nephrology consultation rather than at 
its onset. Finally, we did not link the $K L K 1$ alleles to intermediate phenotypes, such as promoter transcriptional activity or urinary enzymatic activity of KLK1.

In conclusion, in the present study, we provide support for the viewpoint that $K L K 1$ genetic variation plays a role in the development of AKI as well as its associated outcomes. These associations require further exploration, with external validation in more diverse populations. Nonetheless, the KLK1 system may provide valuable genomic biomarkers for the study of AKI, including risk stratification, prognosis, and possible response to therapeutic interventions.

\section{Acknowledgments}

This work has been made possible in part through an International Society of Nephrology-funded Fellowship (to P. Susantitaphong, MD), a grant from the National Institutes of Health (DK083428 to M.C. Perianayagam, PhD), and the UAB-UCSD O'Brien Core Center for Acute Kidney Injury Research (P30 DK079337 to D. O'Connor, MD), especially for assistance in the genotype analyses.

\section{Disclosure Statement}

The authors have no conflicts of interest to disclose.

\section{References}

1 Hsu CY, McCulloch CE, Fan D, Ordonez JD, Chertow GM, Go AS: Community-based incidence of acute renal failure. Kidney Int 2007;72:208-212.

- 2 Hospitalization discharge diagnoses for kidney disease - United States, 1980-2005. MMWR Morb Mortal Wkly Rep 2008;57: 309-312.

3 Wald R, Quinn RR, Luo J, Li P, Scales DC, Mamdani MM, Ray JG: Chronic dialysis and death among survivors of acute kidney injury requiring dialysis. JAMA 2009;302:11791185.

4 Coca SG, Yusuf B, Shlipak MG, Garg AX, Parikh CR: Long-term risk of mortality and other adverse outcomes after acute kidney injury: a systematic review and meta-analysis. Am J Kidney Dis 2009;53:961-973.

5 Lewis J, Salem MM, Chertow GM, Weisberg LS, McGrew F, Marbury TC, Allgren RL: Atrial natriuretic factor in oliguric acute renal failure. Anaritide Acute Renal Failure Study Group. Am J Kidney Dis 2000;36:767774.

6 Friedrich JO, Adhikari N, Herridge MS, Beyene J: Meta-analysis: low-dose dopamine increases urine output but does not prevent renal dysfunction or death. Ann Intern Med 2005; 142:510-524.

7 Jaber BL, Pereira BJ, Bonventre JV, Balakrishnan VS: Polymorphism of host response genes: implications in the pathogenesis and treatment of acute renal failure. Kidney Int 2005;67:14-33.

8 Haase-Fielitz A, Haase M, Bellomo R, Dragun $\mathrm{D}$ : Genetic polymorphisms in sepsis- and cardiopulmonary bypass-associated acute kidney injury. Contrib Nephrol. Basel, Karger, 2007, vol 156, pp 75-91.

-9 Haase-Fielitz A, Haase M, Bellomo R, Lambert G, Matalanis G, Story D, Doolan L, Buxton B, Gutteridge G, Luft FC, et al: Decreased catecholamine degradation associates with shock and kidney injury after cardiac surgery. J Am Soc Nephrol 2009;20:1393-1403.
10 Alam A, O'Connor DT, Perianayagam MC, 18 Higa EM, Schor N, Boim MA, Ajzen H, RaKolyada AY, Chen Y, Rao F, Mahata M, Mahata S, Liangos O, Jaber BL: Phenylethanolamine $\mathrm{N}$-methyltransferase gene polymorphisms and adverse outcomes in acute kidney injury. Nephron Clin Pract 2010;114:c253c259.

11 Perianayagam MC, Liangos O, Kolyada AY, Wald R, MacKinnon RW, Li L, Rao M, Balakrishnan VS, Bonventre JV, Pereira BJ, et al: NADPH oxidase p22phox and catalase gene variants are associated with biomarkers of oxidative stress and adverse outcomes in acute renal failure. J Am Soc Nephrol 2007;18:255263.

12 Kolyada AY, Tighiouart H, Perianayagam MC, Liangos O, Madias NE, Jaber BL: A genetic variant of hypoxia-inducible factor- $1 \alpha$ is associated with adverse outcomes in acute kidney injury. Kidney Int 2009;75:13221329.

13 Jaber BL, Rao M, Guo D, Balakrishnan VS, Perianayagam MC, Freeman RB, Pereira BJ: Cytokine gene promoter polymorphisms and mortality in acute renal failure. Cytokine 2004;25:212-219.

14 Yousef GM, Diamandis EP: The new human tissue kallikrein gene family: structure, function, and association to disease. Endocr Rev 2001;22:184-204.

15 Song CK, Martinez JA, Kailasam MT, Dao TT, Wong CM, Parmer RJ, O'Connor DT: Renal kallikrein excretion: role of ethnicity, gender, environment, and genetic risk of hypertension. J Hum Hypertens 2000;14:461468.

16 Bodin S, Chollet C, Goncalves-Mendes N, Gardes J, Pean F, Heudes D, Bruneval P, Marre M, Alhenc-Gelas F, Bouby N: Kallikrein protects against microalbuminuria in experimental type I diabetes. Kidney Int 2009;76:395-403.

-17 Ardiles LG, Figueroa CD, Mezzano SA: Renal kallikrein-kinin system damage and salt sensitivity: insights from experimental models. Kidney Int Suppl 2003;86:S2-S8. mos OL: Role of the prostaglandin and kallikrein-kinin systems in aminoglycoside-induced acute renal failure. Braz J Med Biol Res 1985;18:355-365.

19 Chao J, Zhang JJ, Lin KF, Chao L: Adenovirus-mediated kallikrein gene delivery reverses salt-induced renal injury in Dahl salt-sensitive rats. Kidney Int 1998;54:1250-1260.

20 Bledsoe G, Crickman S, Mao J, Xia CF, Muraka$\mathrm{mi} \mathrm{H}$, Chao L, Chao J: Kallikrein/kinin protects against gentamicin-induced nephrotoxicity by inhibition of inflammation and apoptosis. Nephrol Dial Transplant 2006;21:624-633.

21 Bledsoe G, Shen B, Yao YY, Hagiwara M, Mizell B, Teuton M, Grass D, Chao L, Chao J: Role of tissue kallikrein in prevention and recovery of gentamicin-induced renal injury. Toxicol Sci 2008; 102:433-443.

$\checkmark 22$ Kang SW, Shih PA, Mathew RO, Mahata M, Biswas N, Rao F, Yan L, Bouchard J, Malhotra $\mathrm{R}$, Tolwani A, et al: Renal kallikrein excretion and epigenetics in human acute kidney injury: expression, mechanisms and consequences. BMC Nephrol 2011;12:27.

23 Song Q, Chao J, Chao L: DNA polymorphis$\mathrm{ms}$ in the $5^{\prime}$-flanking region of the human tissue kallikrein gene. Hum Genet 1997;99:727734.

24 Lee-Chen GJ, Liu KP, Lai YC, Juang HS, Huang SY, Lin CY: Significance of the tissue kallikrein promoter and transforming growth factor- $\beta_{1}$ polymorphisms with renal progression in children with vesicoureteral reflux. Kidney Int 2004;65:1467-1472.

25 Yu H, Song Q, Freedman BI, Chao J, Chao L, Rich SS, Bowden DW: Association of the tissue kallikrein gene promoter with ESRD and hypertension. Kidney Int 2002;61:10301039.

26 Levy MM, Fink MP, Marshall JC, Abraham E, Angus D, Cook D, Cohen J, Opal SM, Vincent JL, Ramsay G: 2001 SCCM/ESICM/ACCP/ ATS/SIS International Sepsis Definitions Conference. Crit Care Med 2003;31:1250-1256. 
$>27$ Knaus WA, Draper EA, Wagner DP, Zimmerman JE: APACHE II: a severity of disease classification system. Crit Care Med 1985;13: 818-829.

28 Knaus WA, Wagner DP: Multiple systems organ failure: epidemiology and prognosis. Crit Care Clin 1989;5:221-232.

29 Levey AS, Bosch JP, Lewis JB, Greene T, Rogers N, Roth D: A more accurate method to estimate glomerular filtration rate from serum creatinine: a new prediction equation. Modification of Diet in Renal Disease Study Group. Ann Intern Med 1999;130:461-470.

30 Mehta RL, Kellum JA, Shah SV, Molitoris BA, Ronco C, Warnock DG, Levin A: Acute Kidney Injury Network: report of an initiative to improve outcomes in acute kidney injury. Crit Care 2007;11:R31.
31 Zhang L, Rao F, Wessel J, Kennedy BP, Rana BK, Taupenot L, Lillie EO, Cockburn M, Schork NJ, Ziegler MG, et al: Functional allelic heterogeneity and pleiotropy of a repeat polymorphism in tyrosine hydroxylase: prediction of catecholamines and response to stress in twins. Physiol Genomics 2004; 19:277-291.

32 O'Connor DT, Barg AP, Amend W, Vincenti F: Urinary kallikrein excretion after renal transplantation: relationship to hypertension, graft source, and renal function. Am J Med 1982;73:475-481.

33 Funaki N, Kuroda M, Sudo J, Takeda R: Urinary prostaglandins and kallikrein in the course of acute renal failure. Prostaglandins Leukot Med 1982;9:387-399.
34 Basile DP, Fredrich K, Alausa M, Vio CP, Liang M, Rieder MR, Greene AS, Cowley AW Jr: Identification of persistently altered gene expression in the kidney after functional recovery from ischemic acute renal failure. Am J Physiol Renal Physiol 2005;288:F953-F963.

35 Hagiwara M, Shen B, Chao L, Chao J: Kallikrein-modified mesenchymal stem cell implantation provides enhanced protection against acute ischemic kidney injury by inhibiting apoptosis and inflammation. Hum Gene Ther 2008,19:807-819.

36 Tu L, Xu X, Wan H, Zhou C, Deng J, Xu G, Xiao X, Chen Y, Edin ML, Voltz JW, et al: Delivery of recombinant adeno-associated virusmediated human tissue kallikrein for therapy of chronic renal failure in rats. Hum Gene Ther 2008;19:318-330. 